\title{
AN EXPERIMENTAL APPROACH TO THE DETERMINATION OF COMPARATIVE EFFICIENCY OF INSULIN AND CONVULSION THERAPY
}

\author{
BY
}

\author{
H. A. PALMER, Major, R.A.M.C. \\ (ReCEIVEd 23Rd February, 1942)
}

THE literature of hypoglycæmic and convulsant therapies has now reached imposing proportions. It would appear that whereas insulin therapy is finding more statistical justification in treating "Dementia Præcox," convulsant therapy, especially now that we have curare available, is establishing a special claim for consideration in the affective disorders of the later age groups.

The question of their comparative utility in the hands of the same investigator is still a justifiable field for research. My experience with cardiazol is of much longer duration than my experience with insulin, while my experience with electrically induced convulsions is necessarily short.

The case material of this research comprehends the intake of a military mental hospital and differs considerably from that of the civilian English mental hospital. It approximates to that of the Woodside or Maudsley material in this country and the Phipps, Philadelphia, and two larger New York clinics in the U.S.A.

Such military material has the advantage of dealing with relatively healthy male adults within the age periods 20 to 50 , and in general covers a prognostically favourable group of patients.

A large proportion of the patients were sad, and ill on account of their sadness, but viewed as clinical syndromes, they showed schizophrenia characterized by autistic modes of thought and the frequent occurrence of bewilderment. Finally, it may be said that there was underlying hysteria in nearly all the cases, in the sense that the illness had meaning, though subconscious, for the personality.

Military material does not lend itself to orthodox classification and any attempt to do so results in therapeutic wastage.

The method of selection for inclusion in the experiment was as follows : If a patient was admitted whose prognosis did not seem immediately favourable or, as in the case of the more completely syntonic syndromes, who had not responded to a regime of narcosis therapy; or if the patient's conduct or clinical characteristics had serious effect on his immediate well-being, future progress or ward atmosphere, that patient was in most instances subjected to a course of insulin or convulsant therapy. On 10th January, 1941, 7 per cent. of patients in hospital were receiving insulin therapy and 13 per cent. were 
receiving convulsant therapy, making a total of 20 per cent. on shock therapy; and 5 per cent. were on narcosis therapy.

The method of allocation to either of the two therapies was as follows: Every alternate case was given insulin or cardiazol, for 40 consecutive cases. The next 10 cases in order were given cardiazol, the following 10 cases insulin, and the final 30 cases were given electrical convulsions. A small group of 10 controls intervened between the first 60 cases and the final 30 cases. This control part of the experiment had to be discontinued; it threatened a choking of the clinic's turnover, which in war-time is an important consideration, and produced an unfavourable effect on ward atmosphere and the efficiency of the personnel.

The sole purpose of the enquiry was to effect a comparison between the individual therapies. Permanence was outside its scope. The convulsant regime was continued until the patient was symptom free, and was usually given three times a week on alternate days. The mean number of convulsions given was 10 per patient.

The insulin regime was given over a period of a month and on the average included 20 comas whose duration lasted an hour. The depth of coma produced can only be stated in terms of the fact that it reached the limit of safety in most cases. In 571 comas, 18 fits, 10 prolonged and two irreversible comas occurred.

The table on p. 12 sets out the results achieved:

Each patient was allotted a score. Ten marks were given for apparent recovery to full economic efficiency and full remission of symptoms. The total possible score was therefore 300 in each group.

The results of this experiment may be stated as follows: The convulsant and insulin technique produced approximately equal numbers of remissions and cures, but the convulsant group showed a small superiority. This finding was confirmed by the superior yield of recoveries following a second alternate therapy in which previously unsuccessfully treated cases are submitted to the other forms of therapy. The results with convulsant therapy are achieved more rapidly, more economically as regards apparatus and drugs, staff time, and period of in-patient treatment. No clear deductions appear justifiable concerning the type of case which might appear to do better under one as opposed to the other therapy. The impression was formed that a previous regime of narcotization gave a better outlook for subsequent therapy by either method-possibly especially the convulsant methods. The graduation made possible by insulin, though it was assumed to render such therapy susceptible of application to certain patients whose cardio-vascular apparatus might contra-indicate convulsant therapy, is partially countered by the cases in which collapse on small doses of insulin was followed by successfully carried out convulsant regime.

The most interesting clinical observation was the frequency with which convulsant treated patients in the course of their treatment would quite suddenly shift the topic of their preoccupation, as they commenced to improve. Thus, a hypochrondriacal man, previously preoccupied with his abdomen, 


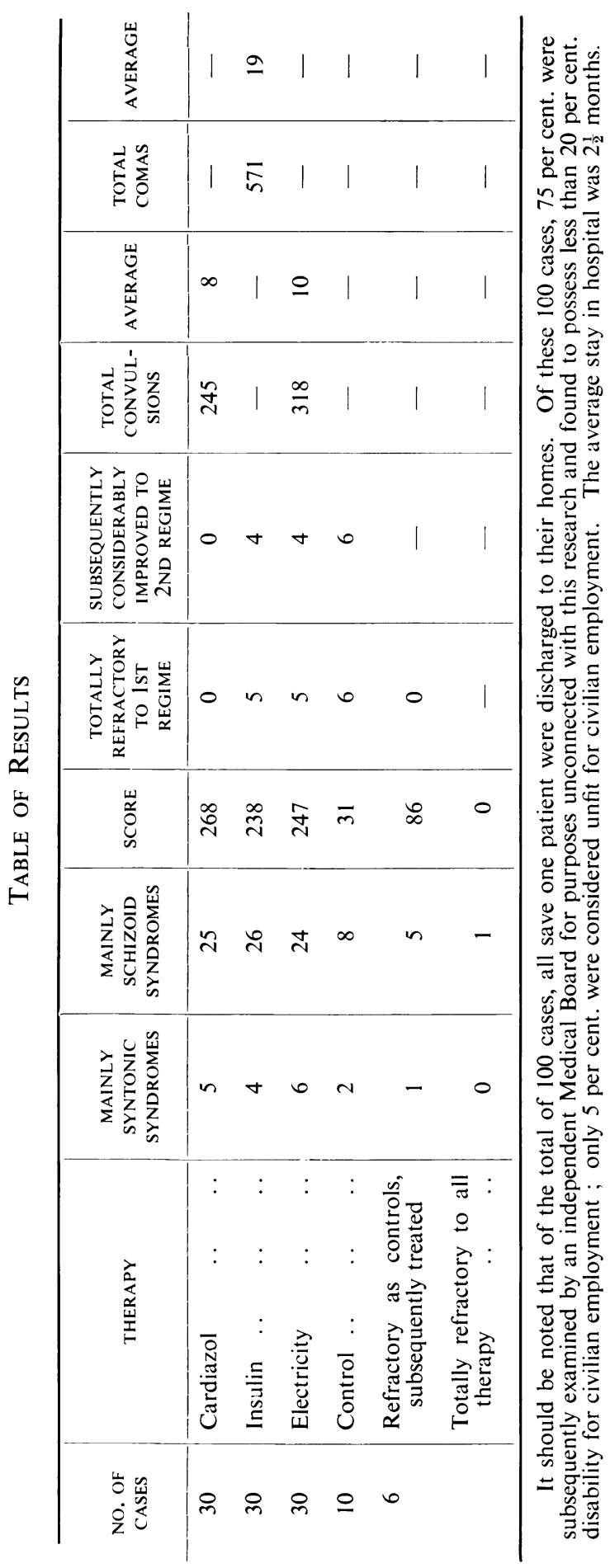


began to discuss his wife's infidelity; a hitherto confused man began to discuss homosexual practices, and finally ceased to be concerned about these in turn; a clerk, previously exhibiting obsessional modes of thought revolving around past sexual misdemeanours, began to discuss his disappointment concerning promotion in the Army.

This sudden shift was not characteristic in the insulin group who exhibited more archaic content in the post-comatose phase.

In this clinic consequent upon the above findings insulin is only given to cases proved refractory to convulsant therapy and cases with poor physique. Approximately one patient receives insulin for every five receiving convulsions.

There remains the problem of spinal fractures complicating convulsant treatment, which in my experience continues to be met with in not less than 15 per cent. of cases. In July 1939 I first advocated (Palmer, 1939) and used curare as a means of controlling this complication. This work was apparently entirely successful and was carried out with the help of Dr. Keale in the psychiatric department of Dr. Noel Harris at the Middlesex Hospital. The outbreak of war put a temporary stop to this work which was inspired by Ranyard West's work in 1936 in this country on tetanus. Meanwhile, in a less disturbed clinical atmosphere in U.S.A., similar work was published (Bennett, 1940), with the result that a marketable product has become available.

\section{Summary}

A method of comparing insulin and convulsion therapy in mixed military cases under otherwise standard conditions was applied to 100 patients selected from amongst 637 admissions to a military hospital. The results show a very nearly equal efficiency for the two methods, but with the convulsant methods slightly more efficient, very much cheaper, and easier to apply. Occasional cases reacted well to one form of therapy, having previously shown no reaction to the other. Electrically induced convulsions produced results as efficiently as peptazol induced convulsions. There is slight evidence that cardiazol produces better results than electricity.

To Captains Tredgold, Graham, and Smith I am indebted for the fullest co-operation in enabling the research to be carried through over a prolonged period.

\section{REFERENCES}

Bennett, A. E. (1940). J. Amer. med. Ass., 114, 322.

Palmer, H. A. (1939). Lancet. 2, 181.

West, R. Ranyard (1936). Lancet, 1, 12. 